\title{
Different methods for the evaluation of surface water quality: The Case of the Liao River, Liaoning Province, China
}

\author{
Lei Zhang ${ }^{1 *}$ \\ 1 Graduate School of Global Environmental Studies, Sophia University \\ *Corresponding Author, Email: zhangleisophia@163.com
}

Received: Dec 15, 2016; Accepted: Jan 15, 2017

Key words: Water Quality Index, Liao River, Water Quality Management

\begin{abstract}
The water-quality index is a grading system for presenting water-quality data and comparing water of varying quality. It can be used in water quality trend analyses and presents valuable information to policy makers, managers, and other nontechnical people. For exploring water quality and identifying the main pollution parameter in the lower reaches of Liao River, Single Factor Evaluation (SFE) method in the form of a Comprehensive Water Pollution Index (CWPI), the Nemerow-Sumitomo Water Quality Index (NWQI), and the Comprehensive Water Quality Identification Index (CWQII) method were used to evaluate water quality in lower reaches of Liao River, Liaoning province, China. The results proved that at Zhaoquan river and Wailiao river the water quality status was good, and Pangxiegou river and Qingshui river showed unsatisfactory water quality status. The major pollution indicator in lower reaches of Liao River was petroleum, and compared with the other assessment methods, CWQII was found to give more useful and objective information, and it is worth further promoting water quality inspections in lower reaches of Liao River. Finally, according to the distribution of industry in the Liao river basin, this study makes some relevant suggestions for sustainable development in the future.
\end{abstract}

\section{INTRODUCTION}

Water is a very important resource for living organisms and human society (Huang, 2015). Without water, existence of man would be threatened (Danquah, Abass, \& Nikoi, 2011). The quality of deteriorating water has been a growing source of concern for the international community (Gyamfi et al., 2013). The issues of water quality have become a common challenge to many countries (WEPA Secretariat (Institute for Global Environmental Strategies (IGES), 2015). In order to prevent water pollution, many countries have issued policies to address its sources, and one very significant link was the evaluation of water environment quality (Ouyang, 2005). In recent years in Asian countries, evaluation of surface water quality has become a critical issue (Yan et al., 2015). According to the Outlook issued by Water Environmental Partnership in Asia (WEPA), the evaluation methodologies applied in Asian countries can be divided into three types (WEPA Secretariat (Institute for Global Environmental Strategies (IGES), 2015). The first type is the water 
quality monitoring data that are directly compared to water quality standards, thus judging whether the water can be used. In Asia, this method has been used by Vietnam and Cambodia because it is simple and easy to utilize, but this is only a primary stage of water quality evaluation. The second type is used by countries like Korea, the Philippines and Japan, whose governments determine whether or not the quality of a water body satisfies the Environmental Quality Standard and is expressed as a percentage. The third type are countries like the People's Republic of China, Malaysia and the Kindom of Thailand, and involves categorizing monitoring sites based on the results of water quality testing and the sites are classified according the water quality standard.

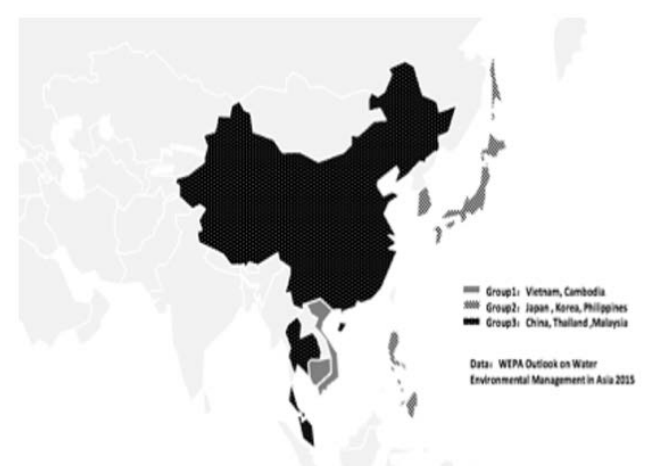

Figure 1. Water quality evaluation methodology in Asian countries

China began to evaluate surface water quality in the 1980s. The first environmental standard of surface water quality was issued in 1983 (Wang et al., 2014). After three revisions, a new standard was formulated in 2002 (Pong, 2007). According to the National Standard of Environmental Quality, the Ministry of Environmental Protection (MEP) issued technical specification requirements for environmental quality assessment of surface water in 2004 and 2012 (The Ministry of Environmental Protection of the People's Republic of China (MEP), 2002). In these technical requirements, the Single Factor Evaluation (SFE) method was used to evaluate surface water quality. However , because this method only considers the single most significant factor, the SFE method is limited in its ability to characterize the conditions of surface water quality (Ji, Dahlgren, \& Zhang, 2016). Even when general water quality is improved, this method may not identify improvements in water quality, and cannot provide effective bases for formulating environmental protection rules and regulations (Xu, Z.-X., 2005).

Water quality evaluation is one of the basic tasks of an environmental protection administration, and researchers have designed numerous approaches for evaluating surface water quality. The comprehensive evaluation of water quality has attracted a lot of interest in recent years $(\underline{\mathrm{Xu}}$,

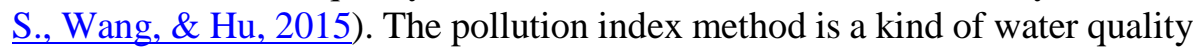
evaluation method stemming from the 1970s (Prati, Pavanello, \& Pesarin, 1971), The pollution index methods include a single factor pollution index method and comprehensive pollution index method (Abbasi \& Abbasi, 2012). Liu et al. (2011) used a pollution index method to evaluate the water quality in the coastal waters of Bohai and both Chemical Oxygen Demand (COD) and phosphate were main pollution factors. However, this method cannot judge water quality class according to Chinese national standards (Yin \& Xu, 2008; Ban et al., 2014).

The Nemerow-Sumitomo Water Quality Index method (NWQI) was put forward by Dr. Nemerow and Sumitomo in the 1970s (Nemerow, 1974). Until 
now, this method was also used for water quality evaluation of underground water by China's environmental protection department (GB/T 14848-93 n.d.). From 2015, the Guangzhou Environmental Protection Bureau started to apply the Nemerow-Sumitomo index of water quality evaluation for surface water. In a paper by $\underline{\mathrm{Xu}}, \mathrm{B}$., Lin, and Mao (2014), the single factor method and Nemerow-Sumitomo index method were used to analyze the water quality of Taihu Lake. They found that the Nemerow-Sumitomo index method was more suitable to for reflecting the comprehensive situation of water quality. However, the overall water quality condition's classification is not identified by Nemerow-Sumitomo pollution index intuitively and cannot judge surface water quality when the water quality is worse than a class 5 (Li, Y.-S. et al., 2009; Ji, Dahlgren, \& Zhang, 2016).

In addition to the methods mentioned above, there are other methods, such as the principal component analysis method (Ouyang, 2005) and the fuzzy analysis method (Gao \& Jin, 2005), however these cannot be used to determine whether the composite water quality allows for the environmental functions of surface water nor to identify which water quality parameters exceed the Chinese national standards, and cannot reflect the practical situation of river water quality in China (Xu, Z.-X., 2005; Ji, Dahlgren, \& Zhang, 2016).

Xu, Z.-X. (2005) proposed a water quality identification index method in 2005. This method can be used to judge whether water polluted by a single pollutant can meet the water quality evaluation requirements of current policies, and also judges comprehensive water quality (Yan et al., 2015). Qun et al. (2009) used this method to evaluate the water quality of Dagu River and found this method can be used to evaluate water quality qualitatively and quantitatively. Hao et al. (2013) used this method to assess the water quality of Jinchuan River, Beitang River, Qingan River and Xiyandapu River in Jiangsu. The main pollution factors were Dissolved Oxygen (DO), ammonia, Chemical Oxygen Demand (COD), Biochemical Oxygen Demand (BOD5) and Total Phosphorus (TP).

This study uses 11 monitoring sites in the lower reaches of Liao River basin. To compare the advantages and disadvantages of these methods and seek a better method fit for Liao River, an SFE-based Comprehensive Water Pollution Index (CWPI) method, Nemerow-Sumitomo index method, and Comprehensive Water Quality Identification Index (CWQII) method were all used to evaluate the water quality in the lower reaches of Liao River. The results of which may be helpful for water pollution governance of Liao River.

\section{RESEARCH AREA AND DATA SOURCE}

\subsection{Research Area}

The research area is Liao River, an important river in the Northeast of China (see Figure 2) (Pavlovska, 2014). Since the 1990s, Liao River has been seriously polluted as the development of urbanization and industrialization has grown (Wei et al., 2009). From 2005, due to the "Control Planning of Water Pollution in Liao River" (Shao et al., 2006), the water quality in Liao River has improved. However, compared with other rivers like Chang Jiang River and Zhujiang River, water quality in the Liao River basin has still been poor, especially, in its lower reaches ( $\mathrm{Li}, \mathrm{Y}$. L. et al., 2012). The reason is that there have been many pollutants in the industrial wastewater and domestic water 
from the upper reaches of the basin that have accumulated in its lower reaches (Ma et al., 2015). In this study, six parameters were monitored in 11 sections (see Table 1) from 2011-2013 downstream of Liao River in Panjin City (see Figure. 3). Three methods were used to assess water quality in the lower reaches of the Liao river system in Panjin City: an SFE-based Comprehensive Water Pollution Index (CWPI) method, Nemerrow-Sumitomo Water Quality Index method (NWQI), and Comprehensive Water Quality Identification Index method (CWQII) were used.

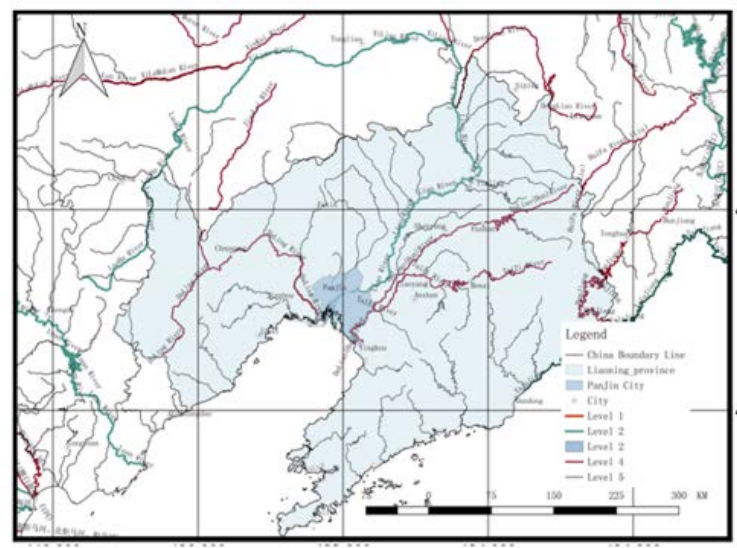

Figure 2. Lower Reaches of Liao River

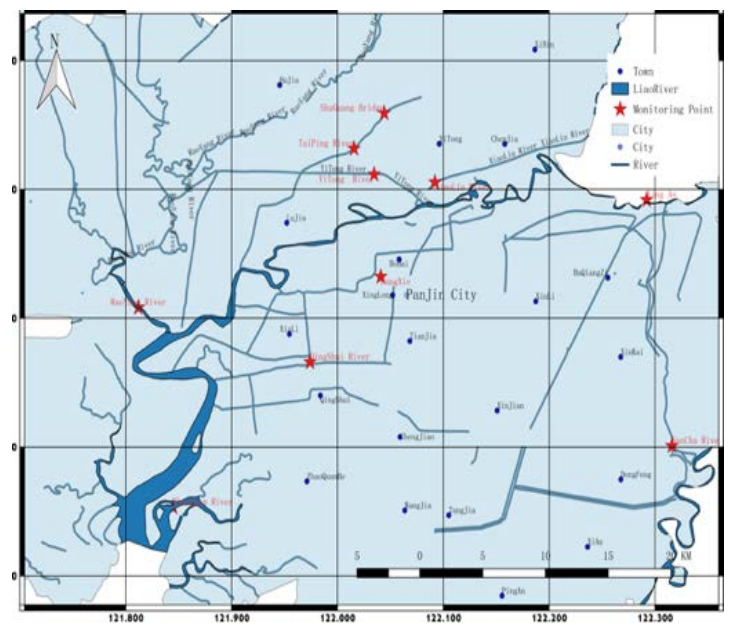

Figure 3. Lower Reaches of Liao River

Table 1. Sampling locations of Liao River in Panjin City

\begin{tabular}{clll}
\hline Sample & Name & Latitude & Longitude \\
\hline A1 & Xingan River & 41.1918 & 122.292 \\
A2 & Shuguang River & 41.2588 & 122.03416 \\
A3 & Zhaoquan River & 40.953301 & 121.844699 \\
A4 & Sancha River & 41.004205 & 122.418441 \\
A5 & Raoyang River & 41.102409 & 121.82899 \\
A6 & Pangxie River & 41.132216 & 122.040859 \\
A7 & Yitong River & 41.192631 & 122.018654 \\
A8 & Xiaoliu River & 41.202074 & 122.093107 \\
A9 & Taiping River & 41.234874 & 122.013327 \\
A10 & Qingshui River & 41.065906 & 121.974067 \\
A11 & Wailiao River & 41.162663 & 122.371668 \\
\hline
\end{tabular}




\subsection{Data Source}

Water quality data from 11 monitoring sites was collected between 2011 and 2013 from the Liao River basin. The municipal environmental department of local government's water quality parameters include COD, petroleum, BOD5, ammonia nitrogen, Total Phosphorus and the Permanganate Index. According to the goals of the 'Water Pollution Prevention Action Plan' proposed by China, the proportion of Class 3 water available should be higher than $70 \%$. So this paper adopted the Class 3 criteria as the preferred water quality standard.

\section{METHODS AND MATERIALS}

For water quality evaluation, the SFE method is used according to the maximum membership class's principle (Ji, Dahlgren, \& Zhang, 2016). This determines that if only one parameter exceeds the standard, all functions of the water body will be lost. The formula for the SFA method is:

$$
F=F_{a} \max
$$

$F$ is the class of surface water, which is classified into classes 1 to (see Table 2). The value of the Surface Water Standard Concentration (The Ministry of Environmental Protection of the People's Republic of China (MEP), 2002) for each of the five classes is shown in Table 3. $F_{a}$ is the class of parameter a and $F_{a} \max$ is the maximum class for all of the parameters (from classes 1 to 5).

\section{Table 2. Water Environmental Quality Standard GB3838-MEP}

\begin{tabular}{|c|c|c|c|c|c|}
\hline \multicolumn{6}{|c|}{$\begin{array}{l}\text { Class II - Mainly applicable to class A water source protection area for centralized drinking } \\
\text { water. }\end{array}$} \\
\hline \multicolumn{6}{|c|}{ Class III - Mainly applicable to a water source protection area } \\
\hline \multicolumn{6}{|c|}{$\begin{array}{l}\text { Class IV - Mainly applicable to water bodies for industrial water supply in which there is not } \\
\text { direct human contact with the water. }\end{array}$} \\
\hline \multicolumn{6}{|c|}{ Class V - Mainly applicable to agricultural water supply and landscape requirements. } \\
\hline \multicolumn{6}{|c|}{ Class V+ - Essentially unusable. } \\
\hline \multicolumn{6}{|c|}{ Data from: China’s Ministry of Environmental Protection (MEP) } \\
\hline & Class 1 & Class 2 & Class 3 & Class 4 & Class 5 \\
\hline Permanganate Index (mg/L) & 2.0 & 4.0 & 6.0 & 10.0 & 15.0 \\
\hline $\operatorname{COD}(\mathrm{mg} / \mathrm{L})$ & 15.0 & 15.0 & 20.0 & 30.0 & 40.0 \\
\hline BOD5(mg/L) & 3.0 & 3.0 & 4.0 & 6.0 & 10.0 \\
\hline $\mathrm{NH}_{3}-\mathrm{N}(\mathrm{mg} / \mathrm{L})$ & 0.15 & 0.5 & 1.0 & 1.5 & 2.0 \\
\hline TP(mg/L) & 0.02 & 0.1 & 0.2 & 0.3 & 0.4 \\
\hline Petroleum (mg/L) & 0.05 & 0.05 & 0.05 & 0.5 & 1.0 \\
\hline
\end{tabular}

Data from: China's Ministry of Environmental Protection (MEP)

\subsection{Comprehensive Water Pollution Index (CWPI)}

The Single Factor Evaluation (SFE) method is used to create a Comprehensive Water Pollution Index (CWPI). The SFE (excluding DO) increases with the pollutant's concentration, and its equation is as follows:

$$
I_{a}=\frac{C_{a}}{S_{o a}}
$$


where the pollution index of water quality index $a, C_{a}(\mathrm{mg} / \mathrm{L})$, was the measured concentration of water quality index $a$, and $S_{o a}(\mathrm{mg} / \mathrm{L})$ was the concentration limit of water quality index $a$.

$\boldsymbol{F}_{\boldsymbol{c p} \boldsymbol{i}}$ referred to the arithmetic mean of $n$ water quality indexes. The equation was as follows:

$$
F_{c p i}=\frac{1}{n} \sum_{\mathrm{n}=1}^{n} I_{\mathrm{a}}
$$

$n$ is the number of selected pollutants. In this research $n=6$.

\subsection{Nemerow-Sumitomo Water Quality Index (NWQI)}

The Nemerow-Sumitomo Water Quality Index (NWQI) is a weighted-type water quality index (excluding DO) which takes into account the average and maximum, and its calculation formula is as follows.

$$
\begin{gathered}
F_{n w q i}=\sqrt{\frac{\max \left(I_{a}\right)^{2}+\operatorname{avg}\left(I_{a}\right)^{2}}{2}} \\
\boldsymbol{a v g}\left(\boldsymbol{I}_{\boldsymbol{i}}\right)=\frac{\mathbf{1}}{\boldsymbol{n}} \sum_{\boldsymbol{i}=\mathbf{1}}^{n} \boldsymbol{I}_{\boldsymbol{a}}
\end{gathered}
$$

\subsection{Comprehensive Water Quality Identification Index (CWQII)}

As a relatively new method, the CWQII could be used to evaluate the water quality of surface water. The Single Factor Identification Index (SFII) is a basic part of the CWQII, and its equation was as follows (excludes DO).

$$
P_{S F I}=P_{1} P_{2}
$$

Where $P_{1}$ is between 1 and 5 , corresponding to its water quality, from Class 1 to 5 .

When the index was not the index for dissolved oxygen (DO), the equation was as follows.

$$
\boldsymbol{P}_{2}=\frac{\boldsymbol{C}_{\boldsymbol{a}}-\boldsymbol{S}_{\boldsymbol{a b}}}{\boldsymbol{S}_{\text {abmax }}-\boldsymbol{S}_{\boldsymbol{a b m i n}}} * 10
$$

$C_{a}$ is the concentration of the $a$ th water quality index, and $S_{a b m a x}$ and $S_{a b m i n}$ are the upper limit and lower limit of the concentration interval of Class $b$ water in the $a$ th index, respectively. The equation is as follows:

$$
\begin{gathered}
\boldsymbol{P}_{C}=\boldsymbol{P}_{1} \boldsymbol{P}_{2} \boldsymbol{P}_{3} \boldsymbol{P}_{4} \\
\boldsymbol{P 1 P 2}=\frac{1}{6}\left(\boldsymbol{P}_{\text {COD }_{m n}}+\boldsymbol{P}_{\text {BOD }_{5}}+\boldsymbol{P}_{N H 3-N}+\boldsymbol{P}_{T p}+\boldsymbol{P}_{\text {petroleum }}+\frac{1}{n} \sum_{\boldsymbol{a}=1}^{n} \boldsymbol{P}_{\boldsymbol{a}}\right)
\end{gathered}
$$

$\boldsymbol{P}_{\boldsymbol{C O D}_{\boldsymbol{m} \boldsymbol{n}}}, \boldsymbol{P}_{\boldsymbol{B O D}_{5}}, \boldsymbol{P}_{\boldsymbol{N H 3}-\boldsymbol{N}}$ and $\boldsymbol{P}_{\boldsymbol{T} \boldsymbol{p}}$ are the $P_{S F I}$ of COD, BOD5, $\mathrm{NH}_{3}-\mathrm{N}$ and TP. $a$ refers to other indexes incorporated in the comprehensive water quality evaluation.

$P_{a}$ was the single factor identification index. $\boldsymbol{P}_{3}$ refers to the number of water quality indexes that were worse than the water quality for functional areas in the urban water environment. If $\boldsymbol{P}_{3}=0$, the indexes incorporated in the evaluation all meet the water quality standard for functional areas. If $\boldsymbol{P}_{3}=1$, one index does not achieve the functional area standard. If $\boldsymbol{P}_{3}=2$, two indexes do not meet the standard, and so on. $\boldsymbol{P}_{4}$ was used to judge whether the comprehensive water quality was worse than that of water in a functional area. 
If the comprehensive water quality was better than that in a functional area, $\boldsymbol{P}_{4}=0$. If the water quality exceeded the standards, then:

$$
\boldsymbol{P}_{4}=\boldsymbol{P}_{1}-\boldsymbol{f}_{a}
$$

Where $f_{a}$ refers to the water quality category for water in functional areas of the urban water environment. If $\boldsymbol{P}_{4}=1$, the water quality is one level higher than the standard. If $\boldsymbol{P}_{\mathbf{4}}=2$, the water quality is two levels higher than the standard.

\section{RESULTS AND DISCUSSION}

\subsection{Descriptive Statistics of the Water Quality}

The descriptive statistics of the water quality are shown in Table 4 below. The average concentration of $\mathrm{COD}_{\mathrm{mn}}, \mathrm{COD}, \mathrm{BOD} 5$, Petrtoleum, $\mathrm{NH}_{3}-\mathrm{N}$ and TP were 7.78 (Class 4), 25.56 (Class 4), 6.29 (Class 5), 0.33 (Class 4), 1.19 (Class 4 ) and 0.18 (Class 3), respectively. For COD $_{m n}, 97 \%$ of the samples were Class 3 and only 3\% exceeded Class 4 (Class 5), The lowest concentration of $\mathrm{COD}_{\mathrm{mn}}$ was $6.24 \mathrm{mg} / \mathrm{L}$ and the highest was $10.67 \mathrm{mg} / \mathrm{L}$. COD was worse than $\mathrm{COD}_{\mathrm{mn}}$, only $15 \%$ of the samples were Class 3 and $70 \%$ were Class 4 , while $15 \%$ had Class 5 water quality standards. The lowest was $17.87 \mathrm{mg} / \mathrm{L}$ and the highest was $36.63 \mathrm{mg} / \mathrm{L}$. For BOD5, 3\% of the samples were Class 3, 49\% were Class 4 and $48 \%$ were Class 5 water quality standards. The lowest concentration of BOD5 was $3.70 \mathrm{mg} / \mathrm{L}$ and the highest was $8.67 \mathrm{mg} / \mathrm{L}$. For Petroleum, $0 \%$ of the samples were Class 3, 97\% were Class 4 and $3 \%$ were Class 5 . The lowest concentration of Petroleum was $0.16 \mathrm{mg} / \mathrm{L}$ and the highest was $0.64 \mathrm{mg} / \mathrm{L}$. For $\mathrm{NH}_{3}-\mathrm{N}, 49 \%$ of the samples were Class 3 , $27 \%$ were Class 4 and $15 \%$ were Class 5 . 9\% were worse than Class 5 . The lowest concentration of $\mathrm{NH}_{3}-\mathrm{N}$ was $0.44 \mathrm{mg} / \mathrm{L}$ and the highest was $3.90 \mathrm{mg} / \mathrm{L}$. For TP, $3 \%$ of the samples were Class 1, $79 \%$ were Class 2, and $18 \%$ were Class 3. The lowest concentration of TP was $0.07 \mathrm{mg} / \mathrm{L}$ and the highest was $0.63 \mathrm{mg} / \mathrm{L}$.

Table 4. Descriptive statistics for six parameters (mg/L)

\begin{tabular}{lcccccc} 
& $\mathbf{C O D}_{\mathbf{m n}}$ & $\mathbf{C O D}$ & $\mathbf{B O D 5}$ & Petroleum & $\mathbf{N H}_{\mathbf{3}}-\mathbf{N}$ & $\mathbf{T P}$ \\
\cline { 2 - 8 } $\begin{array}{l}\text { Number of samples } \\
\text { Average }\end{array}$ & 33 & 33 & 33 & 33 & 33 & 33 \\
\cline { 2 - 7 } $\begin{array}{l}\text { Standard Deviation } \\
\text { Minimum }\end{array}$ & 7.78 & 25.56 & 6.29 & 0.33 & 1.19 & 0.18 \\
\cline { 2 - 7 } Maximum & 1.02 & 4.95 & 1.38 & 0.11 & 0.67 & 0.10 \\
\cline { 2 - 7 } & 6.24 & 17.87 & 3.70 & 0.16 & 0.44 & 0.07 \\
\hline
\end{tabular}

\section{2. $\quad$ Single Factor Evaluation (SFE) Method}

Depending on the results of the SFE method (Figure 4), the level of water quality is determined by the worst index. All rivers in the Liao River basin were inferior, Class 4, and the worst water quality was found in the SanCha River (A4) in both 2012 and 2013, and Pangxiegou River (A6) in 2012. The water quality was worse than Class 5 because the surface water quality standard for the concentration of $\mathrm{NH}_{3}-\mathrm{N}$ was Class 5. In addition, the concentration of TP was Class 5 in Pangxiegou River (A6) in 2011. However, this method only considered the most prominent factor $\left(\mathrm{NH}_{3}-\mathrm{N}\right)$ and other factors were weakened, not all factors were considered in the result of water quality evaluation. 


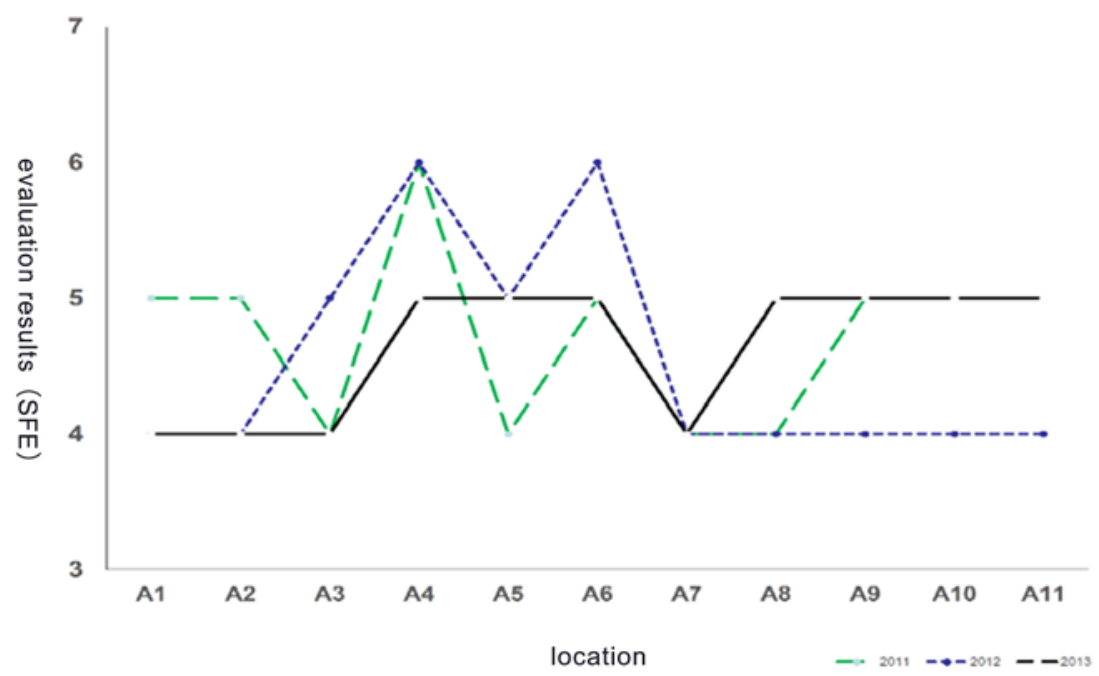

Figure 4. Single Factor Evaluation (SFE) method results

\subsection{Comprehensive Water Pollution Index (CWPI) Method}

Results of the Comprehensive Water Pollution Index (CWPI) are shown in Figure 5 below. These results show the period between 2011-2013. The comprehensive water quality in Pangxiegou River (A6) was the worst, however, according to the CWPI of Pangxiegou River (A6), the level of pollution lightened to a certain extent from 2011-2013 (the CWPI was 2.373, 1.803 and 1.482 in 2011, 2012 and 2013, respectively). The CWPI in Zhao Quan River (A3) was best, and in 2013 the CWPI of Zhao Quan River was 0.851 .

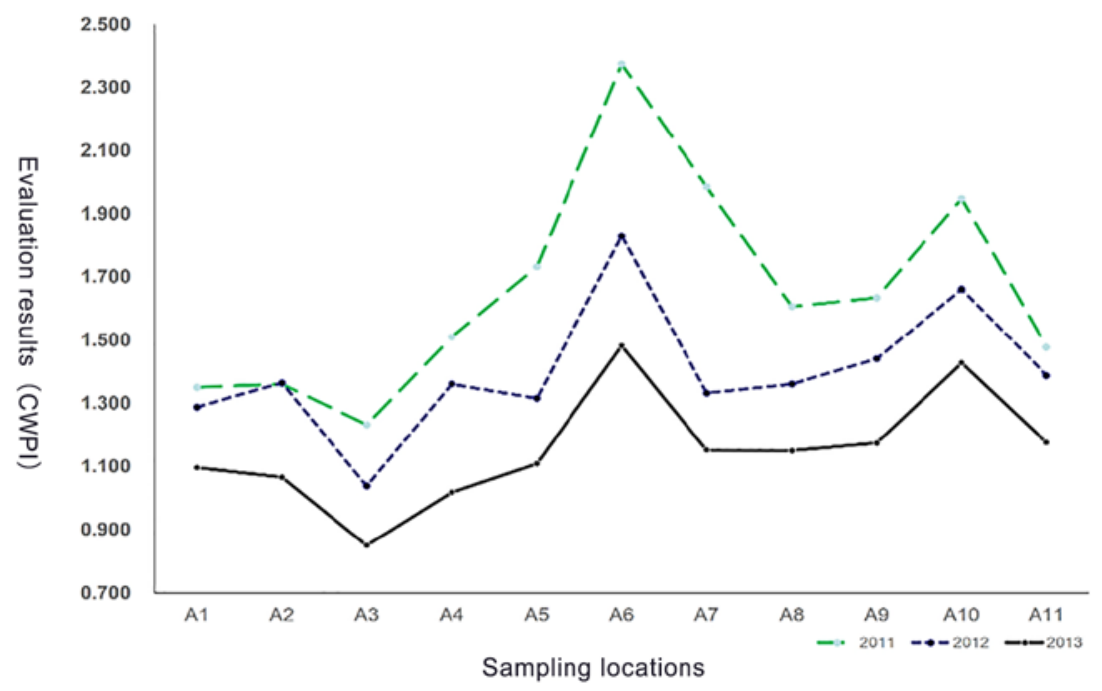

Figure 5. Comprehensive Water Pollution Index (CWPI)

Although the CWPI provides a comprehensive water quality status, this method could not determine the water quality classes according to the surface water environment standards. Moreover, because in the CWPI method all 
factors have the same contribution to the overall water quality, this method cannot reflect a genuine decrease of water quality.

\subsection{Nemerow-Sumitomo Water Quality Index (NWQI) Method}

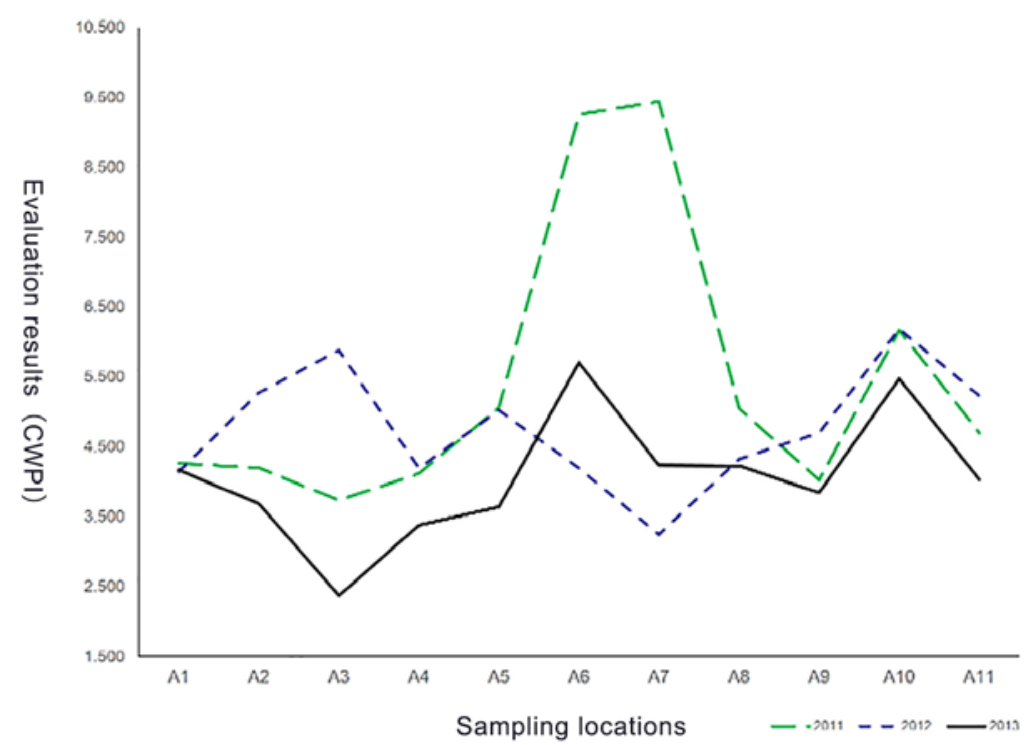

Figure 6. Nemerow-Sumitomo Water Quality Index

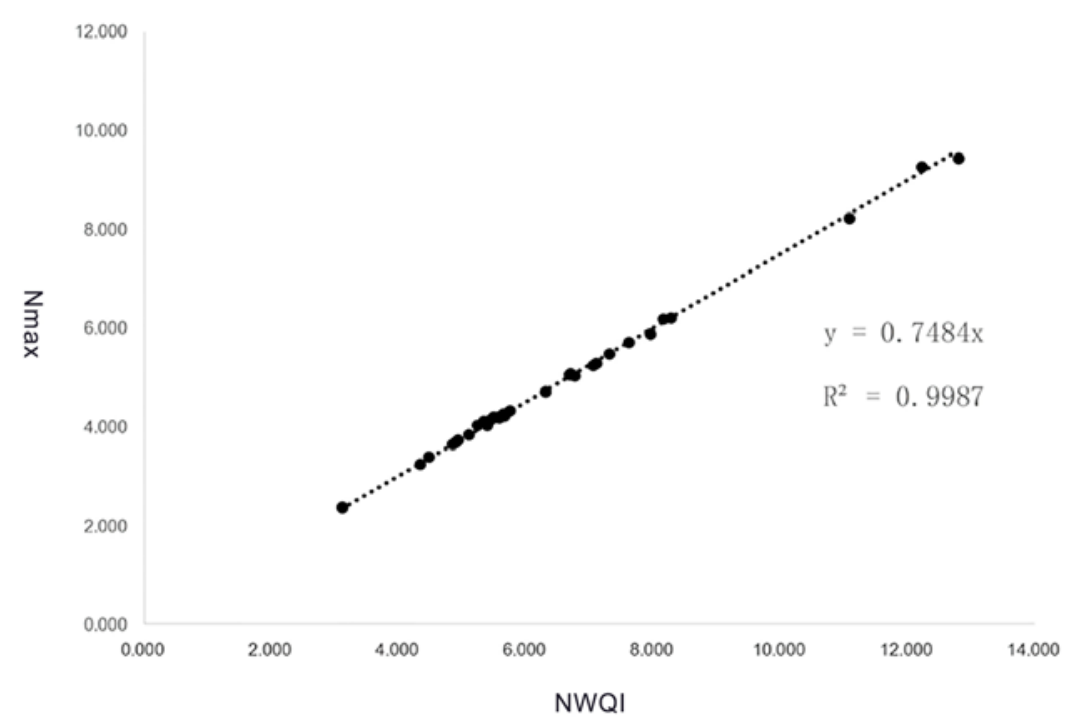

Figure 7. The correlation between Nmax and NWQI

The results of the NWQI are shown in Figure 6. Based on the results, the water quality index of YiTong River (A7) in 2011 was the worst and the water quality of Zhao Quan River in 2013 was the best (NWQI was under 1.0). Compared with the SFE and CWPI, the maximum and average factor contributions of all factors are considered in the NWQI. From the correlation seen between the maximum factor and Nemerow-Sumitomo Index in Figure 
7, it can be seen that this method tends to overemphasize the influence of the maximum evaluation factor $\left(N_{\max }\right)$. When one factor is much higher than the others, the NWQI will be increased. Like the CWPI, this method could not determine the water quality classes according to the surface water environment standards.

\subsection{Comprehensive Water Quality Identification Index (CWQII) Method}

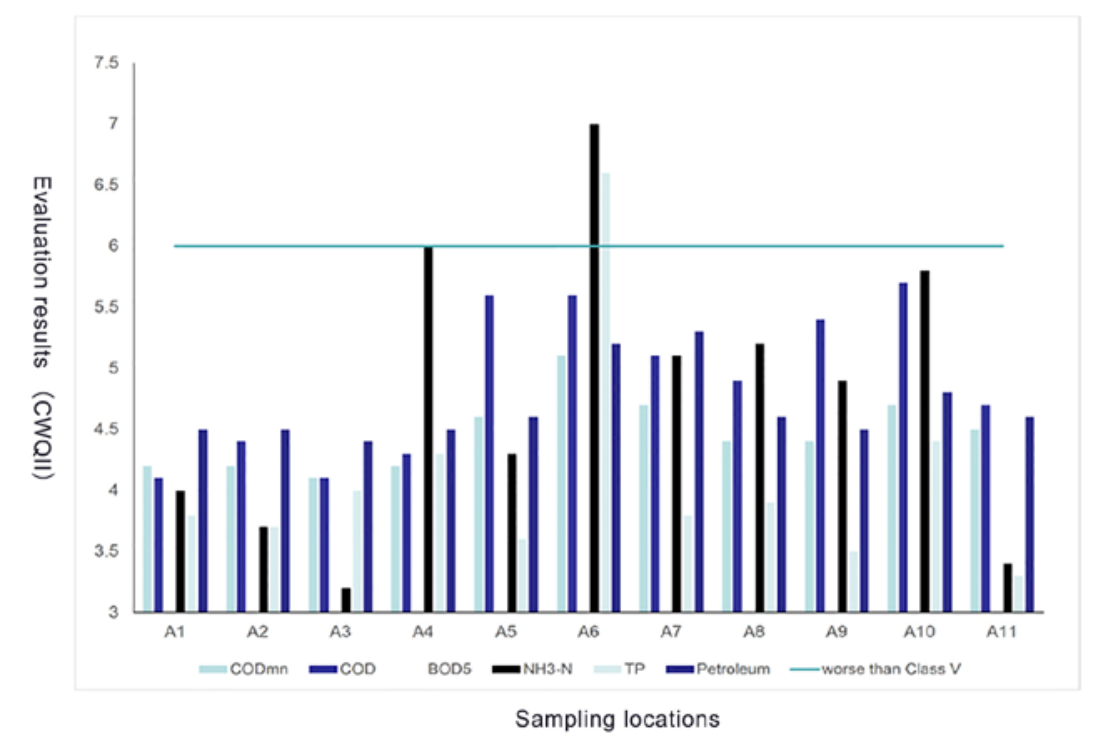

Figure 8. The result of water quality assessment using CWQII on Liao River in 2011.

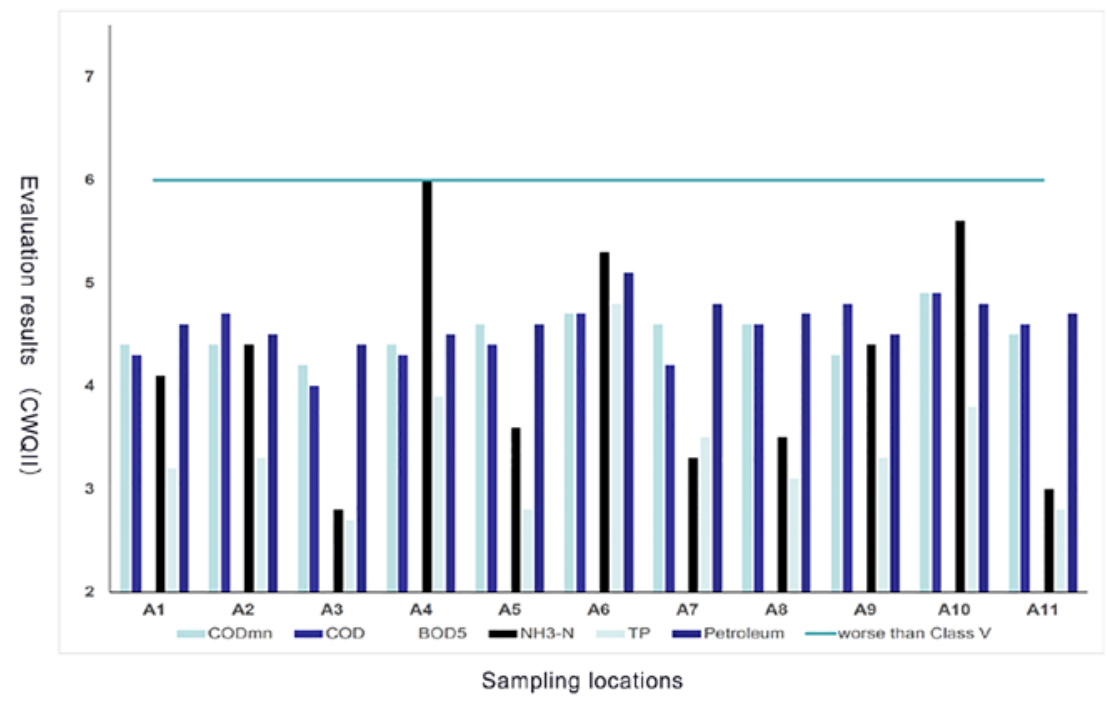

Figure 9. The result of water quality assessment using CWQII on Liao River in 2012.

The water quality classification for each factor was determined according to the CWQII method. The results are shown in Figures 8-10. Like for the SFE method, $\mathrm{NH}_{3}-\mathrm{N}$ in the SanCha River in 2011 and 2012 and in the Pangxiegou River (A6) in 2012 were Class 5 pollutants, as was the TP of Pangxiegou River in 2011. The CWQII of Petroleum and BOD5 showed Petroleum and organics contamination in Liao River and its tributaries. For Petroleum, the lowest 
concentration of was $0.16 \mathrm{mg} / \mathrm{L}$ and the highest was $0.64 \mathrm{mg} / \mathrm{L}$, three times and 12.8 times Class 3, respectively.

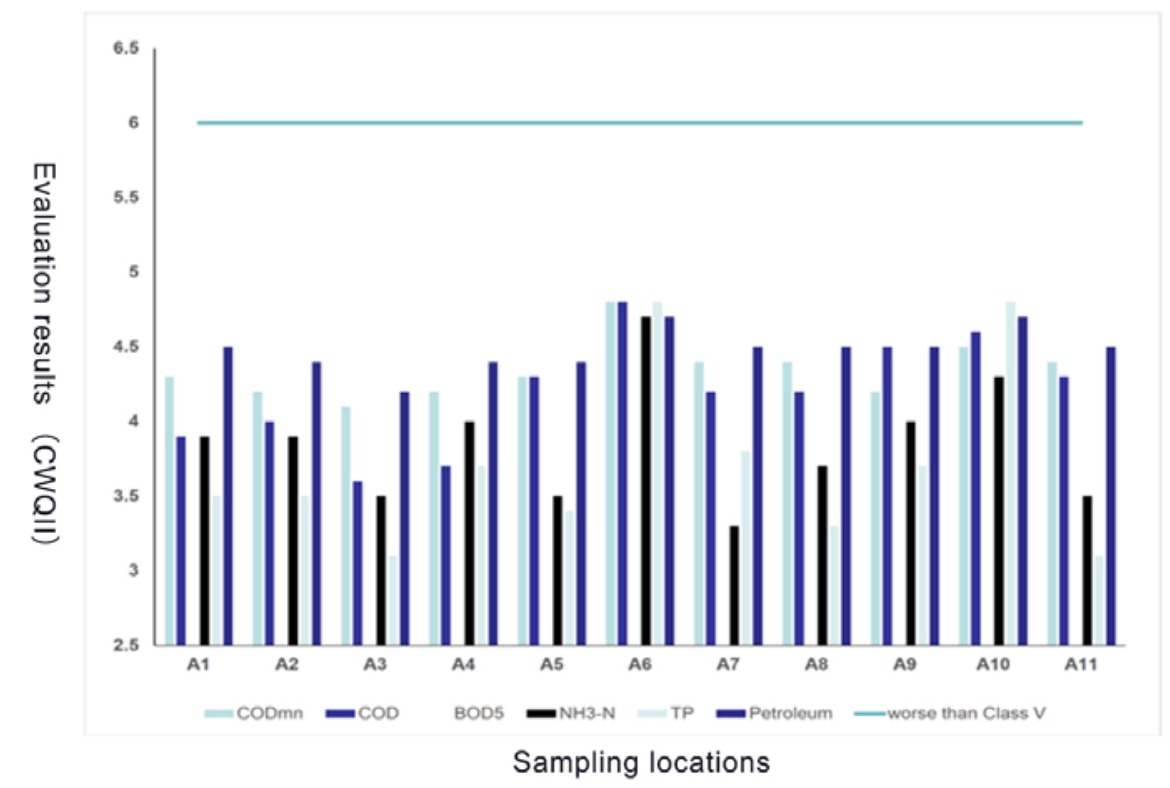

Figure 10. The result of water quality assessment using CWQII on Liao River in 2013.

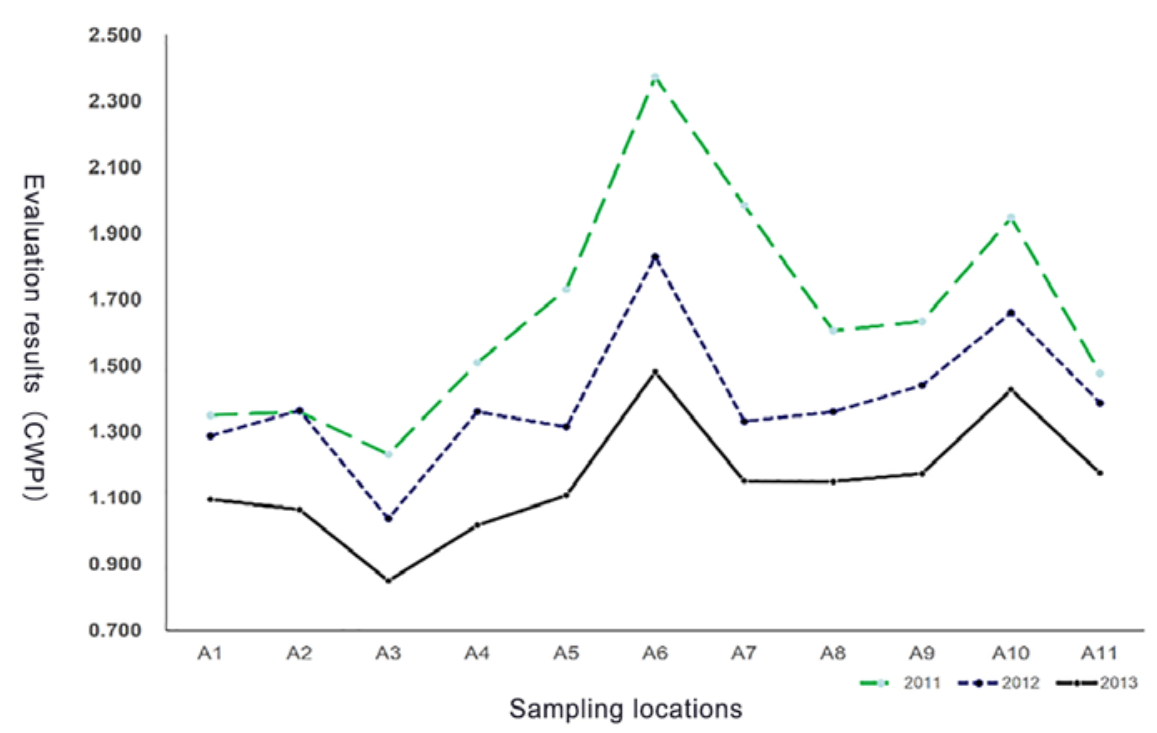

Figure 11. The results of CWQII from 2011-2013.

According to the results of the water quality evaluation by using the CWQII method, the comprehensive water quality of the Zhaoquan River was the best and was the worst for Pangxiegou River (Figure 11). Pangxiegou River was the most polluted water body of Panjin City, where water quality was affected by industrial and domestic sewage. Zhaoquan River is located in the Wetlands Reserve of Liaoning province's delta area and local government have taken a series of important measures to protect the water quality of the wetlands, like creating the Wetland Protection Plan of PanJin City. 
Year to year variation from 2011-2013 is shown in Figure 12. From 20112013, except for Shuguang River in 2011-2012, the water quality improved in all sections. Pangxiegou River, Yitong River (2011-2012) and Sancha River (2012-2013) showed significant improvement (13.4\% 14.4\% and 14.7\%, respectively). It means that the government has done something useful to protect the environment. However, in order to achieve the environmental targets of the 'Water Pollution Prevention Action Plan' by 2020, petroleum and COD5 controls need be improved.

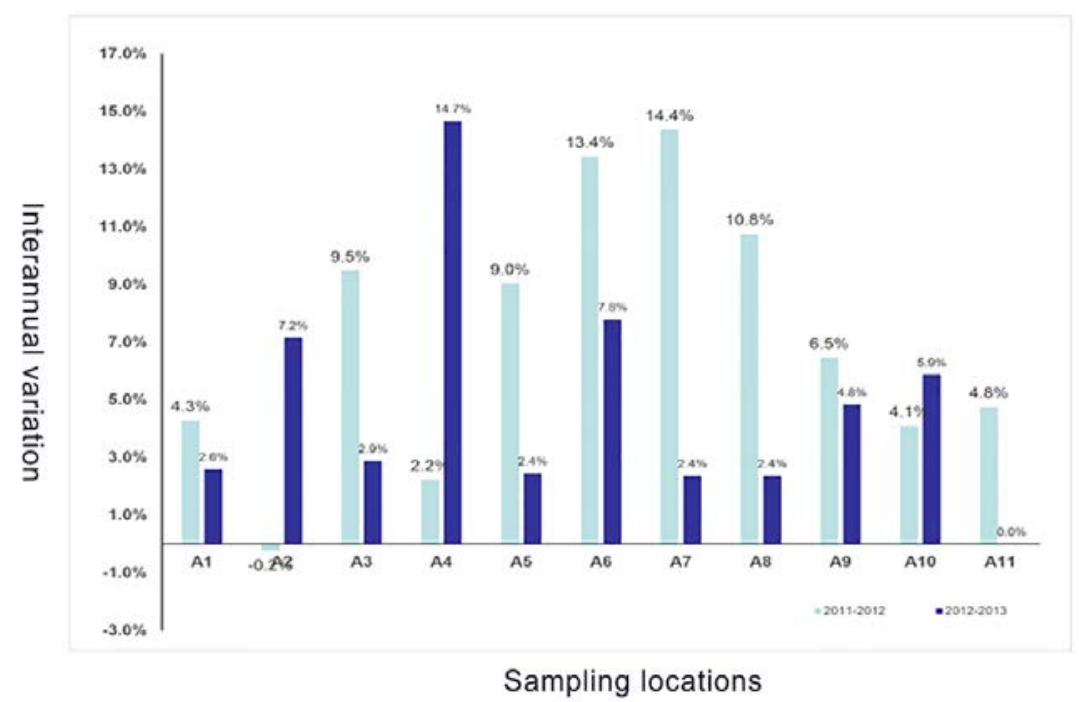

Figure 12. Comprehensive water quality change from 2011-2012 and 2012-2013.

Table 5. Comparison of different methods for the evaluation of surface water quality

\begin{tabular}{lccc} 
& $\begin{array}{l}\text { Considers a } \\
\text { group of factors } \\
\text { instead of using } \\
\text { the worst } \\
\text { evaluation factor }\end{array}$ & $\begin{array}{l}\text { Compares single } \\
\text { and } \\
\text { comprehensive } \\
\text { water qualities } \\
\text { within the same } \\
\text { class }\end{array}$ & $\begin{array}{l}\text { Assesses the } \\
\text { comprehensive } \\
\text { water quality } \\
\text { qualitatively and } \\
\text { quantitatively }\end{array}$ \\
$\begin{array}{l}\text { Single Factor Evaluation } \\
\text { (SFE) Method }\end{array}$ & $\times$ & $\times$ & $\times$ \\
$\begin{array}{l}\text { Comprehensive Water } \\
\text { Pollution Index (CWPI) }\end{array}$ & $\checkmark$ & $\times$ & $\times$ \\
$\begin{array}{l}\text { Method } \\
\text { Nemerow-Sumitomo Water }\end{array}$ & $\checkmark$ & $\checkmark$ & $\times$ \\
$\begin{array}{l}\text { Index (NWQIity } \\
\text { Comprehensive Water } \\
\text { Quality Identification Index } \\
\text { (CWQII) Method }\end{array}$ & $\checkmark$ & $\checkmark$ & $\checkmark$ \\
\hline
\end{tabular}

According to evaluation of the CWQII method, the results showed this method was considered the best method for evaluating the water quality conditions of Liao River and its tributaries, as shown in Table 5.

Firstly, this method can evaluate water quality by using a group of evaluation factors instead of using the worst evaluation factor, so compared with the single factor method, the result of the CWQII is more reasonable. Secondly, compared with other methods, the CWQII can also be used to compare single and comprehensive water qualities within the same class and can also evaluate water quality when the water quality is lower than a Class 5. Thirdly, this method can assess the comprehensive water quality qualitatively 
as well as quantitatively. This method is suitable for assessing water quality in Liao River and can provide useful information for water quality protection.

\section{CONCLUSIONS}

Comparing four methods of evaluating surface water quality, the CWQII is a feasible method for evaluating the water quality conditions of Liao River and its tributaries. The SFE method only considers the most prominent factor and not all factors are considered in the resulting water quality evaluation. This means that the SFE method is limited in its ability to characterize the comprehensive water quality condition. Because of overemphasizing the influence of the maximum factor, the Comprehensive Water Pollution Index method and Nemerow-Sumitomo Water Quality Index method cannot effectively evaluate the comprehensive water quality condition. Moreover, these methods could not determine the water quality classes according to the surface water environment standards of China. The CWQII method was the best method because this method used a group of evaluation factors instead of using only the worst evaluation factor, giving a more balanced result. The CWQII can also be used to compare single factor and comprehensive water quality within the same classification and can evaluate water quality when the classification is lower than a Class 5. This method can also evaluate the comprehensive water quality qualitatively and quantitatively.

According to this method, the $\mathrm{NH}_{3}-\mathrm{N}$ of SanCha River and Pangxiegou River, and the TP of Pangxiegou River, were all lower than Class 5. However, from 2011 to 2013, petroleum and BOD5 were the main pollutants in Liao River. The CWQII showed that the comprehensive water quality of Zhao Quan River was better than in other rivers, and the water quality of Pangxiegou River was worse than other rivers. This is because Pangxiegou River was the most polluted industrial area of PanJin City, where water quality is affected by industrial and domestic sewage. Zhao Quan River is located in the Wetlands Reserve of Liao River delta where local government has adopted a series of measures to protect water quality of the wetland area.

Water quality improved in all rivers except Shuguang River. Pangxiegou River, YiTong River and SanCha River all showed significant improvement. This means the government has done something useful to protect the environment, however, in order to achieve the environment targets of the 'Water Pollution Prevention Action Plan' by 2020, water quality management policies and water environmental controls need to be improved. The CWQII method is an efficient tool to classify the water quality of the river and give rapid and precise information about the situation of the river that can provide useful information for water quality management and decision making.

\section{ACKNOWLEDGEMENT}

I would like to thank my supervisor Guangwei Huang who gave me considerable help by means of suggestion and comments. In addition, I appreciate the contribution to this work made in various ways by my friends and colleagues. 


\section{REFERENCES}

Abbasi, T., \& Abbasi, S. A. (2012). Water Quality Indices. Elsevier.

Ban, X., Yu, C., Pan, B., Ren, X., Du, Y., \& Zhang, L. (2014). "Application of the Cwqii Method and a 2d Water Quality Model to Assess Diversion Schemes for East Lake (Donghu), Wuhan, China". Lake and Reservoir Management, 30(4), 358-370.

Danquah, L., Abass, K., \& Nikoi, A. A. (2011). "Anthropogenic Pollution of Inland Waters: The Case of the Aboabo River in Kumasi, Ghana". Journal of Sustainable Development, 4(6), 103-115.

Gao, H., \& Jin, H. (2005). "Application of Fuzzy Comprehensive Evaluation Method". Pearl River, (6), 50-51.

Gyamfi, C., Boakye, R., Awuah, E., \& Anyemedu, F. (2013). "Application of the Ccme-Wqi Model in Assessing the Water Quality of the Aboabo River, Kumasi-Ghana". Journal of Sustainable Development, 6(10), 1-7. doi: http://dx.doi.org/10.5539/jsd.v6n10p1.

Hao, Y.-Q., Zhang, L., Sun, C., Xie, F., Wu, C., \& Wu, C.-N. (2013). "Study on Evaluation Standard for Malodorous and Black Urban Rivers in Jiangsu". Environmental Science and Technology, 6, 017.

Huang, G. (2015). "From Water-Constrained to Water-Driven Sustainable Development-a Case of Water Policy Impact Evaluation". Sustainability, 7(7), 8950-8964.

Ji, X., Dahlgren, R. A., \& Zhang, M. (2016). "Comparison of Seven Water Quality Assessment Methods for the Characterization and Management of Highly Impaired River Systems". Environmental monitoring and assessment, 188(1), 15-30.

Li, Y.-S., Zhang, Z.-J., Fei, Y.-H., \& Wang, Z. (2009). "Improvement of Nemerow Index Method and Its Application". Water Resources Protection, 25(6), 48-50.

Li, Y. L., Liu, K., Li, L., \& Xu, Z. X. (2012). "Relationship of Land Use/Cover on Water Quality in the Liao River Basin, China". Procedia Environmental Sciences, 13, 1484-1493.

Liu, S., Lou, S., Kuang, C., Huang, W., Chen, W., Zhang, J., \& Zhong, G. (2011). "Water Quality Assessment by Pollution-Index Method in the Coastal Waters of Hebei Province in Western Bohai Sea, China". Marine Pollution Bulletin, 62(10), 2220-2229.

Ma, Y., Zhang, L., Zhao, Y. M., Qin, Y. W., Pan, X. X., Cao, W., . . Yang, C. C. (2015). "Input Characteristics and Pollution Assessment of Nutrients Pollution in the Primary Pollution Source of the Daliao River". Huan jing ke xue= Huanjing kexue, 36(11), 4013-4020.

Nemerow, N. L. (1974). Scientific Stream Pollution Analysis. New York: McGraw-Hill. Retrieved from http://bases.bireme.br/cgibin/wxislind.exe/iah/online/?IsisScript=iah/iah.xis\&src=google\&base=REPIDISCA\&lang $=$ \& $\&$ ext Action=lnk\&exprSearch=160939\&indexSearch=ID.

Ouyang, Y. (2005). "Evaluation of River Water Quality Monitoring Stations by Principal Component Analysis". Water research, 39(12), 2621-2635.

Pavlovska, N. (2014). Strategic Water Management: International Experience and Practices Flood Risk Management. (Vol. III). UNESCO.

Pong, C.-N. (2007). "Water Quality of Reservoirs in Hong Kong". The University of Hong Kong.

Prati, L., Pavanello, R., \& Pesarin, F. (1971). "Assessment of Surface Water Quality by a Single Index of Pollution". Water research, 5(9), 741-751.

Qun, M., Ying, G., Zhiqiang, L., \& Xiaohui, T. (2009). "Application of Comprehensive Water Quality Identification Index in Water Quality Assessment of River". Proceedings of Intelligent Systems, 2009. GCIS'09. WRI Global Congress on, pp. 333-337.

Shao, M., Tang, X., Zhang, Y., \& Li, W. (2006). "City Clusters in China: Air and Surface Water Pollution". Frontiers in Ecology and the Environment, 4(7), 353-361.

The Ministry of Environmental Protection of the People's Republic of China (MEP). (2002). "Environmental Quality Standards for Surface Water (Gb3838-2002)". Retrieved from http://english.mep.gov.cn/standards_reports/standards/water_environment/quality_standar d/200710/W020061027509896672057.pdf.

Wang, F., Li, Q., Wang, X., Qian, Y., Lv, Z., \& Peng, L. (2014). "Comparative Analysis and Generalization on Environmental Quality Standards for Surface Water from 1983 to 2002". Environment and Sustainable Development, (1).

Wei, M., Zhang, N., Zhang, Y., \& Zheng, B. (2009). "Integrated Assessment of River Health Based on Water Quality, Aquatic Life and Physical Habitat". Journal of Environmental Sciences, 21(8), 1017-1027.

WEPA Secretariat (Institute for Global Environmental Strategies (IGES). (2015). "Wepa Outlook on Water Environmental Management in Asia 2015". Retrieved from http://www.wepa-db.net/activities_201504outlook2015.htm. 
Xu, B., Lin, C., \& Mao, X. (2014). "Analysis of Applicability of Nemerow Pollution Index to Evaluation of Water Quality of Taihu Lake". Water Resources Protection, 30(2).

Xu, S., Wang, T., \& Hu, S. (2015). "Dynamic Assessment of Water Quality Based on a Variable Fuzzy Pattern Recognition Model". International journal of environmental research and public health, 12(2), 2230-2248.

Xu, Z.-X. (2005). "Comprehensive Water Quality Identification Index for Environmental Quality Assessment of Surface Water". Tongji Daxue Xuebao/Journal of Tongji University(Natural Science)(China), 33(4), 482-488.

Yan, C.-A., Zhang, W., Zhang, Z., Liu, Y., Deng, C., \& Nie, N. (2015). "Assessment of Water Quality and Identification of Polluted Risky Regions Based on Field Observations \& Gis in the Honghe River Watershed, China". PloS one, 10(3), e0119130.

Yin, H.-L., \& Xu, Z.-X. (2008). "Comparative Study on Typical River Comprehensive Water Quality Assessment Methods". Resources and Environment in the Yangtze Basin, 5, 011. 